\title{
WORK AND HEALTH AMONG NATIVE AND FOREIGN- BORN RESIDENTS IN SWEDEN 1990-2008: A REGISTER- BASED STUDY ON HOSPITALISATION DUE TO COMMON POTENTIALLY WORK-RELATED DISORDERS, DISABILITY PENSION AND MORTALITY
}

Bo Johansson,, Ingvar Lundberg, ${ }^{2}$ Tobias Nordquist, ${ }^{1}$ Magnus Helgesson, ${ }^{2}$ Ola Leijon, ${ }^{3}$ Per Lindberg, ${ }^{4}$ Eva Vingård ${ }^{2}$ Uppsala University Hospital, Uppsala, Sweden; ${ }^{2}$ Uppsala University, Uppsala, Sweden; ${ }^{3}$ Karolinska Institutet, Stockholm, Sweden; ${ }^{4}$ Gävle University, Gävle, Sweden

10.1136/oemed-2011-100382.34

Objectives To study the health status expressed in terms of hospitalisation due to lung, ischemic heart, psychiatric, and musculoskeletal disorders, disability pension and mortality for immigrants compared to native Swedes.

Methods All foreign-born persons in Sweden, 28-47 years old 1990, ( $n=312$ 349) were compared to a random sample of native Swedes $(n=926805)$ in national registers from 1991 to 2008. HRs for men and women from different geographic origin and with different labour market positions were analysed adjusted for age, education, income and years since first immigration.

Results To be a white collar worker in 1990 was more frequent among Swedes and to be outside the labour market both with and without official unemployment status was more frequent among immigrants. Immigrants from the Nordic countries had the least and persons outside the labour market the most favourable health results with regard to studied diseases and disorders. Immigrants from other geographical origin had equal or lower risks of the studied disorders as well as mortality than the Swedes. However, almost all immigrant groups had an increased risk for disability pension. No major differences between men and women were found.

Conclusions To be an immigrant does not mean less good health than being a native Swede, except for immigrants from the Nordic countries. Why immigrants from all origins and in all labour market positions receive more disability pensions ought to be examined more thoroughly, both from a medical point of view and in the context of labour market and social security policies. 